\title{
Living arrangement and coronary heart disease: the JPHC study
}

\section{Citation}

Ikeda, A, H Iso, I Kawachi, K Yamagishi, M Inoue, and S Tsugane. 2008. "Living Arrangement and Coronary Heart Disease: The JPHC Study." Heart 95 (7): 577-83. https://doi.org/10.1136/ hrt.2008.149575.

\section{Permanent link}

http://nrs.harvard.edu/urn-3:HUL.InstRepos:41275557

\section{Terms of Use}

This article was downloaded from Harvard University's DASH repository, and is made available under the terms and conditions applicable to Other Posted Material, as set forth at http:// nrs.harvard.edu/urn-3:HUL.InstRepos:dash.current.terms-of-use\#LAA

\section{Share Your Story}

The Harvard community has made this article openly available.

Please share how this access benefits you. Submit a story.

Accessibility 


\section{Living arrangement and coronary heart disease: The JPHC Study}

Ai Ikeda, $\mathrm{PhD}^{1,2}$, Hiroyasu Iso, $\mathrm{MD}^{1}$, Ichiro Kawachi, $\mathrm{MD}^{2}$, KazumasaYamagishi, $\mathrm{MD}^{3,4}$, Manami Inoue, $\mathrm{MD}^{5}$, Shoichiro Tsugane, $\mathrm{MD}^{5}$ for the JPHC Study Group

${ }^{1}$ Public Health, Department of Social and Environmental Medicine, Graduate School of Medicine, Osaka University. Suita-shi, Osaka, Japan. ${ }^{2}$ Department of Society, Human Development and Health, Harvard School of Public Health, Boston, MA, USA. ${ }^{3}$ Department of Public Health Medicine, Graduate School of Comprehensive Human Sciences, and institute of Community Medicine, University of Tsukuba, Ibaraki, Japan. ${ }^{4}$ Division of Epidemiology and Community Health, School of Public Health, University of Minnesota, Minneapolis, MN, USA.

${ }^{5}$ Epidemiology and Prevention Division, Research Center for Cancer Prevention and Screening, National Cancer Center, Tokyo, Japan.

\section{Address for correspondence:}

Prof. Hiroyasu Iso, MD, PhD, MPH

Public Health, Department of Social and Environmental Medicine, Graduate School of Medicine, Osaka University. 2-2 Yamadaoka, Suita-shi, Osaka 565-0871, Japan. Phone: +81-66879-3911 Fax: +81-6-6879-3919 Email:fvgh5640@mb.infoweb.ne.jp

\section{Address for reprint requests:}

Shoichiro Tsugane, M.D

Epidemiology and Prevention Division, Research Center for Cancer Prevention and Screening, National Cancer Center, 5-1-1 Tsukiji, Chuo-ku, Tokyo 104-0045, Japan, Tel. +81-3-3542-2511 ext. 3385, Fax. +81-3-3547-8578

E-mail: stsugane@ncc.go.jp

Word counts: Abstract: 221 words / Manuscripts: 2,976 words (excluding abstract, tables, references, and appendices)/ Tables: 4 tables/ References: 35 references.

The Corresponding Author has the right to grant on behalf of all authors and does grant on 
behalf of all authors, an exclusive license (or non-exclusive for government employees) on a worldwide basis to the BMJ publishing Group Ltd and its Licensees to permit this article to be published in HEART editions and nay other BMJPGL products to exploit all subsidiary rights as set out in our license (http://heart.bmjjournals.com/ifora/licence.pdf). 


\begin{abstract}
Objectives- Previous studies have suggested that living in a multi-generational household (a type of family structure prevalent in Japan) confers mixed health benefits and stresses, especially for women who report such living arrangements. In this prospective cohort study, we sought to examine the impact of living arrangements on coronary heart disease incidence and mortality as well as all-cause mortality in a large prospective cohort of Japanese population.
\end{abstract} Methods- We examined prospectively the association between living arrangement and risk of coronary heart disease incidence and mortality within a cohort of 90,987 Japanese women and men aged 40-69 years, free of prior diagnosis of cancer and cardiovascular disease. A total of 671 cases of newly diagnosed coronary heart disease, 339 coronary heart disease deaths, and 6,255 all-cause deaths occurred between the baseline questionnaire (1990-1994) and the end of follow-up in January 2004.

Results- After adjustment of potentially confounding variables, women living in multi-generational households (living with spouse-children-parents; or spouse-parents) had 2.0 to 3.0-fold higher risk of coronary heart disease compared to women living with spouses only. Women living with spouses and children also had 2.1-fold higher risk of coronary heart disease incidence compared to married women living without children.

Conclusions- Women in a multi-generational family had a higher risk of coronary heart disease incidence, probably due to stress from multiple family roles.

Key words living arrangement, coronary heart disease, follow-up study 


\section{Introduction}

Family structure and living arrangements are viewed as important determinants of health. For example, married individual have been consistently found to have better health status compared to unmarried individuals living alone-an association that is attributed to not solely to health selection, but also to the protective benefits of marital ties on health (e.g. via financial and social support). ${ }^{1-5}$ Other studies have also examined the deleterious impact of belonging to female-headed households on both the mother's and children's health, mediated by the fact that such households are more likely to experience poverty-related stress. ${ }^{6-16}$

In contrast to studies of marriage and single female-headed households, there have been fewer studies of the health consequences of other family structures. In particular, many Asian societies are marked by a high prevalence of multi-generational family structures, i.e. households in which three generations (grandparents, parents, and children) co-reside. Such household structures are believed to confer a mix of benefits (in the form of inter-generational transfer of care-giving and social support) as well as stresses. For example, Takeda et al. found that women belonging to multi-generational households in Japan were simultaneously at higher risk of sedentary behavior and not receiving regular health check-ups, but also showed lower prevalence of cigarette smoking as well as heavy drinking compared to women living alone or within nuclear families. ${ }^{17}$ In other words, women belonging to multi-generational households exhibit a mixed pattern of damaging as well as protective health behaviors; yet to our knowledge, no study has examined the net consequence of these patterns for major health outcomes such as disease incidence or mortality.

At the same time, Japanese society has been undergoing major shifts, including rapid population aging (and with it, rising demand for elder care), combined with declining marriage and fertility rates, as well as an increase in the proportion of persons living alone. ${ }^{18}$ The proportion of multi-generational households in Japan decreased from 16\% in 1970 to $9 \%$ in 2000, while that of married couples co-residing with their parents and/or parents-in-law also 
decreased from $18 \%$ in 1970 to $11 \%$ in $2000 .{ }^{19}$ Meanwhile, the proportion of persons living alone increased from $20 \%$ in 1980 to $28 \%$ in $2000,{ }^{19}$ and is further estimated to rise to about 35\% by $2025 .^{20}$ The population health implications of these changes in family structure and living arrangements remain unclear.

Gender differences also need to be considered in projecting the health consequences of changing family structure. Due to a general shortage of labor (which is itself attributed to the steep decline in the fertility rate), as well as the rise in women's autonomy achieved through higher educational attainment, more Japanese middle-aged women are employed full-time than ever before. ${ }^{20}$ Yet the burden of domestic labor (including child care and care of aging relatives) continues to fall primarily on women, even as their work force participation has increased. ${ }^{21}$ Since many Japanese middle-aged women continue feel a strong sense of filial responsibility toward their aging parents and/or parents-in-law, ${ }^{17}$ the rate of co-residing with aging parents among women aged 45-49 years has even increased slightly (29.5\% in 1993, 30.4\% in 1998, $36.7 \%$ in 2003) although the corresponding rate among married couples overall has decreased. ${ }^{17,22}$

A growing number of studies have reported that men and women who live alone, are unmarried, and socially isolated are at increased risk of the onset and progression of cardiovascular disease. ${ }^{23-27}$ However, much less has been documented about the health consequences of family structure and living arrangement in relation to cardiovascular morbidity and mortality. In the present study, we sought to examine the gender-specific relationships between living arrangement and coronary heart disease incidence and as well as all-cause mortality in a large prospective cohort of the Japanese population. 


\section{Materials and Methods}

\section{Study cohort}

The first cohort of the Japan Public Health Center-based Prospective Study (JPHC Study) was initiated in 1990 (Cohort I) while the second cohort was initiated in 1993 (Cohort II) within 11 public health center areas throughout the country. ${ }^{28}$ The study population of the present study was defined as all residents $(n=116,896)$ aged $40-59$ years for cohort I and 40-69 years for Cohort II at baseline. Of these residents, 220 residents were excluded due to non-Japanese nationality $(\mathrm{n}=51)$, late reports of emigration occurring before the start of the follow-up period ( $n=166)$, and incorrect birth date $(n=3)$. Therefore, 116,676 residents were remained eligible for the study. A baseline self-administered questionnaire on various lifestyles was given to residents in 1990, 1993 and 1994; 95,374 residents responded to the questionnaire and were included in the study cohort. The overall response rate was $82 \%$. The JPHC study was approved by the institutional review board of the National Cancer Center, Tokyo Japan.

\section{Baseline Questionnaire Survey}

The questionnaire included personal and family medical history, psychosocial factors such as perceived stress, occupation, personality, and lifestyle factors (such as smoking and drinking, diet, and physical activity). Each participant was also asked a question regarding their current living arrangement: “ Are you living with someone (alone, spouse, children, parents, others)?” Those who answered that they were living with a spouse, children and/or parents were further categorized into the following mutually exclusive categories: "living with spouse only", "living with spouse and children”, "living with spouse and parents”, "living with parents and children”, "living with child only", "living with child only”, and "living with spouse, children and parents”. A total of 94,616 participants provided valid response to the question. We also excluded 3,629 participants from the analysis due to previous history of myocardial infarction, angina pectoris, stroke, or cancer at study baseline. Therefore, a total of 43,393 men and 47,594 women were available for the analysis. 


\section{Confirmation of Coronary Heart Disease Incidence}

A total of 78 hospitals were registered within the sampling area of the JPHC cohort. All were major hospitals with the capability of treating patients with acute coronary heart disease (CHD). Physicians blinded to the patent's lifestyle data reviewed the medical records at each hospital. Acute coronary events were included in the study if they occurred after the date of return of the baseline questionnaire and before January 1, 2004.

The details of the surveillance for CHD were described previously. ${ }^{29}$ Briefly, myocardial infarction was confirmed in the medical records according to the criteria of the MONICA (Monitoring Trends and Determinants of Cardiovascular Disease) project, which requires evidence from ECGs, cardiac enzymes, and/or autopsy. When such a workup was not performed but typical chest pain (20 min or longer) was reported, a probable diagnosis of myocardial infarction was made. In the absence of such a diagnosis, deaths that occurred within 1 hour from onset of symptoms were regarded as sudden cardiac deaths.

\section{Confirmation of Coronary Heart Disease Mortality}

All death certificates were centrally to the Ministry of Health, Welfare and Labor and coded for the National Vital Statistics. Registration of death is required by the Family Registration Law and is believed to be complete in Japan. The underlying causes of deaths were defined according to the International Classification of Diseases, 10th Revision [ICD-10 as follows: deaths from CHD (I20 to I25)]. Coronary deaths were included in the analyses if they occurred after the date of return of the baseline questionnaire and before January 1, 2004.

Among the study subjects, 6,112 died, 5,824 moved out of the study areas, and 85 were lost to follow-up within the 10 year follow-up period.

\section{Statistical analysis}

Person-years in the follow-up period were counted from the date of the return of the baseline survey until one of the following endpoints. For the analysis of CHD incidence, person-years were censored at the date of disease diagnosis, the date of emigration from the 
study area, the date of death, or the end of study period (December 31, 2003), whichever come first. For the analysis of CHD deaths, person-years were censored at the date of emigration from the study area, the date of death, or the end of the study period, whichever come first. CHD incidence and death were analyzed separately, and we only counted incidence or mortality event once in each analysis. For persons who were lost to follow-up, the last confirmed date of their presence in the study area was used as the date of censoring.

Analysis of covariance and chi-square tests were used to compare sex-specific age-adjusted mean values and proportions of cardiovascular risk factors. The outcomes for this study were defined as newly occurring CHD incidence and deaths during the study period. Hazard ratios (HR) and their 95\% confidence intervals (95\% CI) were calculated after adjustment for age and other potential confounding factors using Cox proportional-hazards models. Confounding variables included age (years), public health center area, smoking status (never, former, current), ethanol intake (non- and ex-drinkers, less than weekly, <150g/wk, 150-299g/wk, 300-449g/wk, or $>=450 \mathrm{~g} / \mathrm{wk})$, body mass index ( $\mathrm{kg} / \mathrm{m}^{2}$ in quartiles), sports at leisure time ( $<1$ day/mo, 1-3 days/mo, 1-2 days/wk, 3-4 days/wk, or almost every day), and perceived psychological stress (less, moderate, or high). We tested the assumption of proportional hazards by using both time-dependent covariate method and linear correlation test, and found no violation of proportionality. All analyses were conducted using the SAS statistical package Version 9.1 (SAS Institute Inc., Cary, North Carolina). 


\section{Results}

During the 1,037,893 person-years of the follow-up period (median follow-up period=11.0years) for the 90,987 subjects (43,393 men and 47,594 women), a total of 671 cases of newly diagnosed CHD (506 men and 165 women) were included in the analyses for the incidence. For the analyses of mortality, 339 CHD deaths (242 men and 97 women), and 6,255 all cause deaths (4,182 men and 2,073 women) were included during the 1,092,161 person-years of the follow-up period (median follow-up period=11.0 years) for the 90,987 subjects.

We separately examined living arrangement in relation to cardiovascular risk factors among men and women (Table 1). We found that women residing in multi-generational households (i.e. “with spouse and parent”, or “with spouse, parent, and child(ren)” were much less likely to engage in risk behaviors such as cigarette smoking or heavy drinking compared to women living alone or with their spouses only (Table 1). The same patterns were not observed in men residing in multi-generational families. Women residing in multi-generational households were also more likely to report a higher prevalence of stress compared to those living alone or with spouses only. Again, among men, we did not observe such differences. Both men and women residing in multi-generational households were less likely to report being physically active, compared to their counterparts who were living alone or living with spouses only.

Table 2 shows the hazard ratios of CHD incidence according to categories of living arrangement. In Model 1, we adjusted the hazard ratios for age and public health center area only. In Model 2, we additionally adjusted for stress. Finally in Model 3, we adjusted for the full range of covariates, including some (e.g. smoking, drinking, physical activity) that may be considered on the pathway between family structure, stress, and CHD incidence.

Among men, we found little indication of differences in risk of CHD incidence according to living arrangement. By contrast, we found suggestive patterns among women indicating an elevated risk of CHD incidence among those belonging to multi-generational 
families. For example, the multivariable-adjusted HR among women living in 3-generation households (with parents, spouse, and children) was 2.00 (95\% CI: 1.01-3.94) compared to women living with spouses only. Similarly the multivariate HRs among women living with “spouses and parents” and "spouses and children” were 3.03 and 2.11, respectively (both of them statistically significant) (Table 2). Women living only with children (i.e. in female-headed households) were also at twice the risk of CHD incidence (HR=2.00, 95\% CI: 1.16-3.43) compared to women living with spouses.

Table 3 presents the hazard ratios of CHD mortality according to categories of living arrangement. The patterns in this table suggest that living arrangements have a different relationship to coronary mortality compared to coronary disease incidence. Among men, two kinds of family structure stood out as being associated with increased risks of CHD mortality: men living with their parents (HR=2.02, 95\% CI: 1.03-3.98), and men living with “others” (HR=3.78, 95\% CI: 1.95-7.32). A similar excess risk of CHD mortality was also seen among women who lived with their parents (HR=4.94, 95\% CI: 1.81-13.5), although the estimate was only based upon five cases.

Table 4 presents the hazard ratios of all cause mortality according to categories of living arrangement. The results of these models echo the patterns described for coronary disease mortality. Men who lived with their parents, with their children (but not spouses), or with “others” appeared to be at $28-58 \%$ increased risk of total mortality. A similar pattern was also observed in women living with their parents or with "others”. Among neither men nor women did we find an association between multi-generational family structure and all-cause mortality. 


\section{Discussion}

In this large prospective analysis in a Japanese population, we found that after adjustment for potentially confounding variables, women living in multi-generational households (living with spouse-children-parents; or spouse-parents) were at double to triple the risk of CHD incidence compared to women living with spouses only. Women living with spouses and children were also at double the risk of CHD incidence compared to married women living without children. Women belonging to multi-generational households did not appear to be at increased risk of CHD mortality compared to women living with just their spouses. This suggests that although living in multi-generational households may increase the risk of incident disease, it does not affect prognosis following established disease.

Two contrasting theories have been offered concerning the influence of living arrangement on women's health outcomes. Role conflict and role strain theory posits that women are more likely to experience stress (and to adopt risky health behaviors such as smoking and heavy drinking) when they are forced to take on additional roles (i.e. full-time worker and informal caregiver). In contrast to role strain theory, role enhancement theory posits that added roles may benefit women's health via increased access to resources (such as emotional and financial support).

The hypothesized mechanisms underlying the association between the stress from multiple family roles and coronary heart disease prognosis include an unhealthy profile of behaviors (such as smoking and heavy alcohol consumption), as well as exaggerated cardiovascular reactivity to stress through neuro-endocrine mechanisms. ${ }^{30}$ Stress activates neuro-endocrine pathways such as the hypothalamic-pituitary-adrenal (HPA)-axis and the sympathetic adrenal-medullary (SAM) axis. ${ }^{30}$ The long-term activation of these axes in turn induces a sustained increase in cortisol, ${ }^{30}$ norepinephrine secretion, ${ }^{30}$ inflammatory proteins, ${ }^{31}$ platelet abnormalities, ${ }^{32}$ and endothelial dysfunction, ${ }^{33}$ which may ultimately exacerbate other 
cardiovascular risk factors such as hypertension, ${ }^{30}$ heart rate, ${ }^{34}$ hyperlipidemia, ${ }^{30}$ diabetes, ${ }^{30}$ and the progression of atherosclerosis. ${ }^{30}$

A previous study among Japanese subjects found that women living within multi-generational households (i.e., living with spouse, children, and parents) showed a healthier pattern of behavior with respect to avoidance of smoking and heavy drinking compared to women living with spouse alone. ${ }^{17}$ Consistent with that study, we found that women living in multi-generational households were less likely to be current smokers, or heavy alcohol drinkers. The presence of family members, especially parents seems to exercise some measure of social control, i.e., Japanese traditional norms about women smoking and having excessive alcohol consumption, which might be linked to prevent from risk-promoting health behaviors. However, these women were also more likely to report high-perceived stress. The net impact of belonging to a multi-generational household - at least for women - appeared to be deleterious with respect to risk of coronary disease incidence. By comparison, men’s cardiovascular incidence risk did not appear to be affected by their living arrangement.

We note several limitations in the present study. First, reverse causation is possible in the association between men and women who were living with their children, parents, or “others" (but not their spouses) and CHD mortality. Poor health status is a disadvantage in the marriage market, thereby leading to a preponderance of healthy individuals in the married population. ${ }^{35}$ Thus, men and women living only with parents or others may have been doing so because they were already sick, or were being cared for by family members. The elevated risk of CHD mortality among both men and women living only with parents or others in present study could be due to this sort of reverse causation. We note that hazard estimates were not elevated for CHD incidence in these same categories. Second, living arrangement was assessed in our study through a simple question relating to current living arrangement. We did not further inquire about actual exchanges of social support or other resources. Finally, it is possible that there could be over- and/or under- diagnoses in coronary heart disease in the present study. However, 
because our criteria used for coronary heart disease in the present study included myocardial infarction with typical chest-pain (20 min or longer) and sudden deaths that occurred within 1 hour from onset of symptoms, and because everyone had easy access to emergency care under Japanese health insurance system, it would be unlikely that heart disease was over-diagnosed among women living in multi-generational households (e.g. spouse and parents, and spouse, parents and children) and/or under-diagnosed among women living with spouse only. And also, as far as we know no study has shown that heart disease is over-diagnosed or under-diagnosed in Japanese according to living arrangements.

The strengths of our study are its prospective design and large sample size, enabling us to uncover the gender-specific effects of family structure and living arrangements on disease incidence and mortality. To our knowledge, this is the first prospective study to examine the association between living arrangements and disease incidence within individuals residing in multi-generational families.

In conclusion, living in a multigenerational family was associated with a higher risk of CHD incidence in women, probably due to role stress. Our findings have health policy relevance given the current increase in work force participation among women in Japan, decline in the marriage rate as well as the rapid population aging in that society. 


\section{Acknowledgements}

The authors thank all staff members in each study area and in the central office for their painstaking efforts to conduct the baseline survey and follow-up.

\section{Source of Funding:}

This study was supported by Grants-in-aid for Cancer Research and for the Third Term Comprehensive Ten-Year Strategy for Cancer Control from the Ministry of Health, Labor and Welfare of Japan.

\section{Competing interests:}

None declared. 


\section{References}

(1) Wyke S, Ford G. Competing explanations for associations between marital status and health. Soc Sci Med 1992; 34: 523-532.

(2) Joung IM, Stronks K, van de Mheen H, Mackenbach JP. Health behaviours explain part of the differences in self reported health associated with partner/marital status in The Netherlands. J Epidemiol Community Health 1995; 49: 482-488.

(3) Seenman TE. Social ties and health: The benefits of social integration. Ann Epidemiol 1996; 6:442-451.

(4) Murphy M, Glaser K, Grundy E. Marital status and long-term illness in Great Britain. J Marriage Fam 1997; 59: 156-164.

(5) Joutsenniemi K, Martelin T, Martikainen P, Pirkola S, Koskinen S. Living arrangements and mental health in Finland. J Epidemiol Community Health 2006; 60: 468-475.

(6) Lipman EL, Offord DR, Boyle MH. Single mothers in Ontario: sociodemographic, physical and mental health characteristics. CMAJ 1997; 156: 639-645.

(7) Brown GW, Moran PM. Single mothers, poverty and depression. Psychol Med 1997; 27: 21-33.

(8) Shouls S, Whitehead M, Burstrom B, Diderichsen F. The health and socio-economic circumstances of British lone mothers over the last two decades. Popul Trends 1999; 95: 41-46.

(9) Hope S, Power C, Rodgers B. Does financial hardship account for elevated psychological distress in lone mothers? Soc Sci Med 1999; 49: 1637-1649.

(10) Mansfield CJ, Wilson JL, Kobrinski EJ, Mitchell J. Premature mortality in the United States: the roles of geographic area, socioeconomic status, household type, and availability of medical care. Am J Public Health 1999; 89: 893-898.

(11) Hughes ME, Waite L. Health in household context: Living arrangements and health in late middle age. J Health Soc Behav 2002; 43: 1-21. 
(12) Huurre T, Aro H, Rahkonen O. Well-being and health behaviour by parental socioeconomic status: a follow-up study of adolescents aged 16 until age 32 years. Soc Psychiatry Psychiatr Epidemiol 2003; 38: 249-255.

(13) Franz M, Lensche H, Schmitz N. Psychological distress and socioeconomic status in single mothers and their children in a German city. Soc Psychiatry Psychiatr Epidemiol 2003; 38: 59-68.

(14) Spencer N. Maternal education, lone parenthood, material hardship, maternal smoking, and longstanding respiratory problems in childhood: testing a hierarchical conceptual framework. J Epidemiol Community Health 2005; 59: 842-846.

(15) Young LE, Cunningham SL, Buist DS. Lone mothers are at higher risk for cardiovascular disease compared with partnered mothers. Data from the National Health and Nutrition Examination Survey III (NHANES III). Health Care Women Int 2005; 26: 604-621.

(16) Westin M, Westerling R. Health and healthcare utilization among single mothers and single fathers in Sweden. Scand J Public Health 2006; 34: 182-189.

(17) Takeda Y, Kawachi I, Yamagata Z, Hashimoto S, Matsumura Y, Oguri S, Okayama A. Multigenrational family structure in Japanese society: impacts on stress and health behaviors among women and men. Soc Sci Med 2004; 59: 69-81.

(18) Health and welfare statistics association. Annual Statistical Report of National Health Conditions 2004; 51: 35-44.

(19) Ministry of Public Management, Home Affairs, Posts and Telecommunications, Japan, Statistics Bureau. (1970-2000). The Population Census of Japan, 2000.

(20) National Institute of Population and Social Security Research. (2006). Population Statistics of Japan 2006.

(21) Chandola T, Martikainen P, Bartley M, Lahelma E, Marmot M, Michikazu S, Nasermoaddeli A, Kagamimori S. Does conflict between home and work explain the effect of multiple roles on mental health? A comparative study of Finland, Japan, and the UK. Int J 
Epidemiol 2004; 33: 884-893.

(22) National Institute of Population and Social Security Research. (2003). The third national survey on family in Japan, 2003.

(23) Seeman TE, Syme SL. Social networks and coronary artery disease: a comparison of the structure and function of social relations as predictors of disease. Psychosom Med 1987; 49: 341-54.

(24) Berkman LF, Glass T. Social integration, social networks, social support, and health. In: Berkman LF, Kawachi I, eds. Social epidemiology. New York, NY: Oxford University Press, 2000: 137-173.

(25) Vogt TM, Mullooly JP, Ernst D, Pope CR, Hollis JF. Social networks as predictors of ischemic heart disease, cancer, stroke, and hypertension: incidence, survival and mortality. J Clin Epidemiol 1992; 45: 659-666.

(26) Mookadam F, Arthur HM. Social support and its relationship to morbidity and mortality after acute myocardial infarction: systematic overview. Arch Intern Med. 2004 26; 164:1514-1518.

(27) Boden-Albala B, Litwak E, Elkind MS, Rundek T, Sacco RL. Social isolation and outcomes post stroke. Neurology 2005; 64: 1888-1892.

(28) Tsugane S, Sobue T. Baseline survey of JPHC study-design and participation rate. Japan Public Health Center-Based Prospective Study on Cancer and Cardiovascular Diseases. J Epidemiol 2001; 11 (suppl): S24-S29.

(29) Iso H, Kobayashi M, Ishihara J, Sasaki S, Okada K, Kita Y, Kokubo Y, Tsugane S; for the JPHC Study Group. Intake of fish and n3 fatty acids and risk of coronary heart disease among Japanese, The Japan Public Health Center-Based (JPHC) study cohort I. Circulation 2006; 113:195-202.

(30) Rozanski A, Blumenthal JA, Davidson KW, Saab OG, Kubzansky L. The epidemiology, pathophysiology, and management of psychosocial risk factors in cardiac practice. The 
emerging field of behavioral cardiology. J Am Coll Cardiol 2005, 637-651.

(31) Anisman H and Merali Z. Cytokines, stress, and depressive illness. Brain Behav Immun 2002; 16: 513-524.

(32) Grignani G, Pacchiarini L, Zucchella M, Tacconi F, Canevari A, Soffiantino F, Tavazzi L. Effect of mental stress on platelet function in normal subjects and in patients with coronary artery disease. Haemostasis 1992; 22:138-146.

(33) Ghiadoni L, Donald AE, Cropley M, Mullen MJ, Oakley G, Taylor M, O'Connor G, Betteridge J, Klein N, Steptoe A, Deanfield JE. Mental stress induces transient endothelial dysfunction in humans. Circulation 2000; 102: 2473-2478.

(34) Kelsey RM, Blascovich J, Tomaka J, Leitten CL, Schneider TR, Wiens S. Cardiovascular reactivity and adaptation to recurrent psychological stress: effects of prior task exposure. Psychophysiology 1999; 36: 818-831

(35) Goldman N, Hu Y. Excess mortality among the unmarried: a case study of Japan. Soc Sci Med 1993; 36:533-46. 


\section{Appendix}

\section{Study Group Members}

Members of the Japan Public Health Center-based Prospective Study (JPHC Study, principal investigator: S. Tsugane) Group are: S. Tsugane, M. Inoue, T. Sobue, and T. Hanaoka, National Cancer Center, Tokyo; J. Ogata, S. Baba, T. Mannami, A. Okayama, and Y. Kokubo, National Cardiovascular Center, Osaka; K. Miyakawa, F. Saito, A. Koizumi, Y. Sano, I. Hashimoto, and T. Ikuta, Iwate Prefectural Ninohe Public Health Center, Iwate; Y. Miyajima, N. Suzuki, S. Nagasawa, Y. Furusugi, and N. Nagai, Akita Prefectural Yokote Public Health Center, Akita; H. Sanada, Y. Hatayama, F. Kobayashi, H. Uchino, Y. Shirai, T. Kondo, R. Sasaki, Y. Watanabe, Y. Miyagawa, and Y. Kobayashi, Nagano Prefectural Saku Public Health Center, Nagano; Y.

Kishimoto, E. Takara, T. Fukuyama, M. Kinjo, M. Irei, and H. Sakiyama, Okinawa Prefectural Chubu Public Health Center, Okinawa; K. Imoto, H. Yazawa, T. Seo, A. Seiko, F. Ito, and F. Shoji, Katsushika Public Health Center, Tokyo; A. Murata, K. Minato, K. Motegi, and T. Fujieda, Ibaraki Prefectural Mito Public Health Center, Ibaraki; K. Matsui, T. Abe, M. Katagiri, and M. Suzuki, Niigata Prefectural Kashiwazaki and Nagaoka Public Health Center, Niigata; M. Doi, A. Terao, Y. Ishikawa, and T. Tagami, Kochi Prefectural Chuo-higashi Public Health Center, Kochi; H. Sueta, H. Doi, M. Urata, N. Okamoto, and F. Ide, Nagasaki Prefectural Kamigoto Public Health Center, Nagasaki; H. Sakiyama, N. Onga, H. Takaesu, and M. Uehara, Okinawa Prefectural Miyako Public Health Center, Okinawa; F. Horii, I. Asano, H. Yamaguchi, K. Aoki, S. Maruyama, M. Ichii, and M. Takano, Osaka Prefectural Suita Public Health Center, Osaka; Y. Tsubono, Tohoku University, Miyagi; K. Suzuki, Research Institute for Brain and Blood Vessels Akita, Akita; Y. Honda, K. Yamagishi, and S. Sakurai, University of Tsukuba, Ibaraki; M. Kabuto, National Institute for Environmental Studies, Ibaraki; M. Yamaguchi, Y. Matsumura, S. Sasaki, and S. Watanabe, National Institute of Health and Nutrition, Tokyo; M. Akabane, Tokyo University of Agriculture, Tokyo; T. Kadowaki, University of Tokyo; M. Noda, International Medical Center of Japan, Tokyo; Y. Kawaguchi, Tokyo Medical and Dental University, Tokyo; Y. 
Takashima, Kyorin University, Tokyo; K. Nakamura, Niigata University, Niigata; S.

Matsushima and S. Natsukawa, Saku General Hospital, Nagano; H. Shimizu, Sakihae Institute, Gifu; H. Sugimura, Hamamatsu University, Shizuoka; S. Tominaga, Aichi Cancer Center Research Institute, Aichi; H. Iso, Osaka University, Osaka; M. Iida, W. Ajiki, and A. Ioka, Osaka Medical Center for Cancer and Cardiovascular Disease, Osaka; S. Sato, Osaka Medical Center for Health Science and Promotion, Osaka; E. Maruyama, Kobe University, Hyogo; M. Konishi, K. Okada, and I. Saito, Ehime University, Ehime; N. Yasuda, Kochi University, Kochi; S. Kono, Kyushu University, Fukuoka. 
Table 1. Distribution of baseline in a cohort of 90,988 men and women according to the category of living arrangement.

\begin{tabular}{|c|c|c|c|c|c|c|c|c|c|}
\hline & \multicolumn{9}{|c|}{ The category of living arrangement } \\
\hline & Alone & Spouse & $\begin{array}{c}\text { Spouse + } \\
\text { Parent }\end{array}$ & $\begin{array}{c}\text { Spouse + } \\
\text { Child }\end{array}$ & $\begin{array}{c}\text { Spouse + } \\
\text { Child + } \\
\text { Parent }\end{array}$ & Parent & Child & $\begin{array}{l}\text { Child + } \\
\text { Parent }\end{array}$ & Others \\
\hline Men, $\mathrm{n}$ & 1,343 & 8,309 & 1,566 & 18,355 & 8,978 & 1,650 & 1,641 & 941 & 610 \\
\hline Age, year & 52.1 & 57.6 & 54.5 & 51.1 & 47.9 & 46.1 & 53.0 & 47.7 & 50.9 \\
\hline Ethanol intake, g/week & 223.8 & 252.4 & 239.2 & 246.5 & 245.5 & 198.1 & 252.8 & 244.7 & 189.3 \\
\hline Body mass index, kg/m2 & 23.5 & 23.6 & 23.6 & 23.6 & 23.4 & 23.2 & 23.4 & 23.3 & 23.1 \\
\hline Current smoker, \% & 57.3 & 50.4 & 51.5 & 51.9 & 53.3 & 55.2 & 58.5 & 57.3 & 55.2 \\
\hline Physical activity, \% & 22.1 & 20.9 & 15.6 & 19.4 & 16.4 & 14.4 & 16.6 & 12.6 & 14.6 \\
\hline History of hypertension, \% & 19.1 & 17.0 & 19.3 & 19.2 & 18.8 & 18.3 & 18.6 & 18.5 & 17.2 \\
\hline History of diabetes, \% & 6.6 & 6.8 & 6.5 & 6.5 & 6.4 & 6.3 & 5.6 & 4.7 & 5.8 \\
\hline High Stress, \% & 22.8 & 22.5 & 24.1 & 22.8 & 23.2 & 11.2 & 17.7 & 16.3 & 18.4 \\
\hline Economically inactive, \% & 13.6 & 6.4 & 2.9 & 4.4 & 3.8 & 13.8 & 6.7 & 4.7 & 16.3 \\
\hline Women, $\mathrm{n}$ & 2,281 & 9,804 & 1,582 & 18,612 & 6,840 & 1,053 & 5,401 & 1,335 & 686 \\
\hline Age, year & 57.8 & 56.6 & 53.0 & 50.8 & 47.3 & 49.4 & 53.5 & 48.6 & 54.6 \\
\hline Ethanol intake, g/week & 42.3 & 17.9 & 12.4 & 12.3 & 6.5 & 13.2 & 27.5 & 19.6 & 18.4 \\
\hline Body mass index, kg/m2 & 23.3 & 23.5 & 23.2 & 23.7 & 23.3 & 23.1 & 23.7 & 23.4 & 23.1 \\
\hline Current smoker, \% & 12.8 & 6.3 & 3.1 & 5.1 & 2.7 & 7.4 & 8.8 & 5.6 & 10.0 \\
\hline Physical activity, \% & 20.5 & 20.2 & 14.8 & 16.8 & 14.5 & 16.4 & 15.3 & 13.1 & 16.4 \\
\hline
\end{tabular}




\section{(Cont. table1)}

\begin{tabular}{|c|c|c|c|c|c|c|c|c|c|}
\hline History of hypertension, \% & 17.4 & 17.1 & 15.0 & 19.2 & 17.4 & 16.5 & 19.9 & 17.9 & 17.8 \\
\hline History of diabetes, $\%$ & 3.0 & 3.7 & 2.5 & 3.1 & 2.6 & 3.5 & 3.5 & 3.1 & 4.5 \\
\hline High Stress, \% & 18.5 & 16.0 & 25.0 & 17.0 & 23.3 & 18.0 & 18.4 & 19.3 & 18.3 \\
\hline Economically inactive, \% & 32.7 & 37.8 & 24.2 & 36.2 & 22.6 & 29.9 & 31.1 & 18.6 & 34.2 \\
\hline
\end{tabular}


Table 2. Age-adjusted and multivariable hazard ratio and 95\% confidence interval for CHD incidence according to the category of living arrangement.

\begin{tabular}{|c|c|c|c|c|c|c|c|c|c|}
\hline & \multicolumn{9}{|c|}{ The category of living arrangement } \\
\hline & Alone & Spouse & $\begin{array}{c}\text { Spouse + } \\
\text { Parent }\end{array}$ & $\begin{array}{c}\text { Spouse + } \\
\text { Child }\end{array}$ & $\begin{array}{c}\text { Spouse + } \\
\text { Child + } \\
\text { Parent }\end{array}$ & Parent & Child & $\begin{array}{l}\text { Child + } \\
\text { Parent }\end{array}$ & Others \\
\hline \multicolumn{10}{|l|}{ Men } \\
\hline Person-years & 11,952 & 86,611 & 17,701 & 205,195 & 106,644 & 18,840 & 19,217 & 11,826 & 6,538 \\
\hline Coronary heart disease, $n$ & 18 & 114 & 17 & 220 & 85 & 17 & 20 & 12 & 3 \\
\hline Model $1 *$ & $1.39(0.84-2.29)$ & 1.0 & $0.90(0.54-1.50)$ & $1.07(0.84-1.37)$ & $1.05(0.77-1.43)$ & $1.19(0.70-2.03)$ & $0.92(0.57-1.49)$ & $1.23(0.67-2.28)$ & $0.45(0.14-1.43)$ \\
\hline Model $2^{\dagger}$ & $1.39(0.84-2.29)$ & 1.0 & $0.90(0.54-1.50)$ & $1.08(0.84-1.37)$ & $1.05(0.77-1.43)$ & $1.23(0.72-2.09)$ & $0.93(0.57-1.52)$ & $1.26(0.68-2.32)$ & $0.46(0.15-1.45)$ \\
\hline Model $3^{\ddagger}$ & $1.23(0.74-2.02)$ & 1.0 & $0.90(0.54-1.50)$ & 1.06(0.83-1.35) & $1.04(0.76-1.41)$ & $1.06(0.63-1.81)$ & $0.84(0.52-1.37)$ & $1.17(0.63-2.16)$ & $0.41(0.13-1.29)$ \\
\hline \multicolumn{10}{|l|}{ Women } \\
\hline Person-years & 24,078 & 108,984 & 18,560 & 218,769 & 82,463 & 12,188 & 63,907 & 16,753 & 7,668 \\
\hline Coronary heart disease, $n$ & 14 & 27 & 8 & 70 & 14 & 1 & 28 & 2 & 1 \\
\hline Model $1{ }^{*}$ & $1.87(0.98-3.58)$ & 1.0 & $2.81(1.27-6.24)$ & $2.03(1.28-3.22)$ & $1.86(0.94-3.67)$ & $0.68(0.09-5.06)$ & $2.03(1.18-3.47)$ & $1.16(0.27-4.94)$ & $0.56(0.08-4.14)$ \\
\hline Model $2^{\dagger}$ & $1.86(0.97-3.56)$ & 1.0 & $2.84(1.28-6.32)$ & $2.04(1.29-3.24)$ & $1.88(0.95-3.71)$ & $0.69(0.09-5.08)$ & $2.03(1.19-3.48)$ & $1.17(0.27-5.00)$ & $0.56(0.08-4.14)$ \\
\hline Model $3^{\ddagger}$ & $1.77(0.92-3.39)$ & 1.0 & 3.03(1.36-6.75) & 2.11(1.33-3.35) & $2.00(1.01-3.94)$ & $0.70(0.09-5.17)$ & $2.00(1.16-3.43)$ & $1.17(0.27-4.98)$ & $0.55(0.07-4.06)$ \\
\hline
\end{tabular}

* Multivariate hazard ratios were adjusted for age and public health center (phc) area. $\dagger$ Multivariate hazard ratios were adjusted for age, phc area and

stress. $\ddagger$ Multivariate hazard ratios were adjusted for age, phc area, stress, and health behavior variables (smoking, alcohol drinking, physical activity,

body mass index). CHD indicates coronary heart disease. 
Table 3. Age-adjusted and multivariable hazard ratio and 95\% confidence interval for CHD mortality according to the category of living arrangement.

\begin{tabular}{|c|c|c|c|c|c|c|c|c|c|}
\hline & \multicolumn{9}{|c|}{ The category of living arrangement } \\
\hline & Alone & Spouse & $\begin{array}{c}\text { Spouse + } \\
\text { Parent }\end{array}$ & $\begin{array}{c}\text { Spouse + } \\
\text { Child }\end{array}$ & $\begin{array}{c}\text { Spouse + } \\
\text { Child + } \\
\text { Parent }\end{array}$ & Parent & Child & $\begin{array}{l}\text { Child + } \\
\text { Parent }\end{array}$ & Others \\
\hline \multicolumn{10}{|l|}{ Men } \\
\hline Person-years & 15,168 & 92,754 & 18,343 & 219,068 & 110,213 & 19,798 & 20,098 & 12,249 & 7,257 \\
\hline Coronary heart disease, $n$ & 10 & 57 & 5 & 98 & 32 & 11 & 15 & 3 & 11 \\
\hline Model $1 *$ & $1.52(0.77-2.99)$ & 1.0 & $0.57(0.23-1.42)$ & $1.14(0.81-1.61)$ & $1.04(0.65-1.66)$ & $2.22(1.13-4.37)$ & $1.72(0.96-3.09)$ & $0.87(0.27-2.84)$ & $4.07(2.11-7.86)$ \\
\hline Model $2^{\dagger}$ & $1.52(0.77-2.99)$ & 1.0 & $0.56(0.23-1.41)$ & $1.14(0.81-1.61)$ & $1.03(0.65-1.65)$ & $2.27(1.16-4.48)$ & $1.73(0.97-3.10)$ & $0.88(0.27-2.87)$ & $4.15(2.15-8.01)$ \\
\hline Model $3^{\ddagger}$ & 1.43(0.73-2.81) & 1.0 & $0.57(0.23-1.42)$ & $1.11(0.79-1.57)$ & $1.01(0.63-1.62)$ & $2.02(1.03-3.98)$ & $1.54(0.86-2.76)$ & $0.81(0.25-2.65)$ & $3.78(1.95-7.32)$ \\
\hline \multicolumn{10}{|l|}{ Women } \\
\hline Person-years & 26,234 & 114,718 & 18,951 & 227,703 & 84,105 & 12,790 & 67,036 & 17,300 & 8,373 \\
\hline Coronary heart disease, $n$ & 15 & 19 & 3 & 29 & 5 & 5 & 17 & 3 & 1 \\
\hline Model $1 *$ & 2.78(1.41-5.49) & 1.0 & $1.52(0.45-5.19)$ & $1.26(0.69-2.29)$ & $0.99(0.36-2.77)$ & 4.98(1.83-13.6) & $1.88(0.97-3.67)$ & $2.78(0.80-9.68)$ & $0.82(0.11-6.14)$ \\
\hline Model $2^{\dagger}$ & 2.83(1.43-5.59) & 1.0 & $1.42(0.42-4.84)$ & $1.25(0.68-2.27)$ & $0.95(0.34-2.66)$ & $4.91(1.80-13.4)$ & $1.87(0.96-3.65)$ & $2.71(0.78-9.44)$ & $0.81(0.11-6.08)$ \\
\hline Model $3^{\ddagger}$ & $2.72(1.37-5.38)$ & 1.0 & $1.45(0.42-4.97)$ & $1.26(0.69-2.30)$ & $1.00(0.36-2.79)$ & 4.94(1.81-13.5) & $1.85(0.95-3.62)$ & $2.73(0.78-9.51)$ & $0.80(0.11-6.00)$ \\
\hline
\end{tabular}

* Multivariate hazard ratios were adjusted for age and public health center (phc) area. $†$ Multivariate hazard ratios were adjusted for age, phc area and

stress. $¥$ Multivariate hazard ratios were adjusted for age, phc area, stress, and health behavior variables (smoking, alcohol drinking, physical activity,

body mass index). CHD indicates coronary heart disease. 
Table 4. Age-adjusted and multivariable hazard ratio and 95\% confidence interval for all cause mortality according to the category of living arrangement.

\begin{tabular}{|c|c|c|c|c|c|c|c|c|c|}
\hline & \multicolumn{9}{|c|}{ The category of living arrangement } \\
\hline & Alone & Spouse & $\begin{array}{c}\text { Spouse + } \\
\text { Parent }\end{array}$ & $\begin{array}{c}\text { Spouse + } \\
\text { Child }\end{array}$ & $\begin{array}{c}\text { Spouse + } \\
\text { Child + } \\
\text { Parent }\end{array}$ & Parent & Child & $\begin{array}{l}\text { Child + } \\
\text { Parent }\end{array}$ & Others \\
\hline \multicolumn{10}{|l|}{ Men } \\
\hline Person-years & 15,168 & 92,754 & 18,343 & 219,068 & 110,213 & 19,798 & 20,098 & 12,249 & 7,257 \\
\hline All causes, $n$ & 193 & 1,152 & 136 & 1,636 & 497 & 153 & 244 & 81 & 90 \\
\hline Model $1 *$ & $1.52(1.30-1.77)$ & 1.0 & $0.78(0.66-0.94)$ & $0.97(0.90-1.05)$ & $0.81(0.72-0.90)$ & $1.68(1.41-2.00)$ & $1.39(1.20-1.60)$ & $1.19(0.94-1.50)$ & $1.66(1.34-2.06)$ \\
\hline Model $2^{\dagger}$ & $1.52(1.30-1.77)$ & 1.0 & $0.78(0.66-0.94)$ & $0.97(0.90-1.05)$ & $0.80(0.72-0.90)$ & $1.68(1.40-2.00)$ & $1.39(1.20-1.60)$ & $1.19(0.94-1.50)$ & $1.66(1.33-2.06)$ \\
\hline Model $3^{\ddagger}$ & $1.47(1.26-1.72)$ & 1.0 & $0.79(0.66-0.95)$ & $0.96(0.88-1.04)$ & $0.80(0.71-0.89)$ & $1.56(1.30-1.86)$ & $1.28(1.11-1.47)$ & $1.13(0.89-1.42)$ & $1.58(1.27-1.96)$ \\
\hline \multicolumn{10}{|l|}{ Women } \\
\hline Person-years & 26,234 & 114,718 & 18,951 & 227,703 & 84,105 & 12,790 & 67,036 & 17,300 & 8,373 \\
\hline All causes, $\mathrm{n}$ & 162 & 540 & 49 & 695 & 167 & 70 & 293 & 47 & 50 \\
\hline Model $1{ }^{*}$ & $1.15(0.96-1.37)$ & 1.0 & $0.76(0.56-1.01)$ & $0.95(0.84-1.06)$ & $0.87(0.72-1.04)$ & $1.95(1.51-2.50)$ & $1.07(0.92-1.23)$ & $1.03(0.76-1.40)$ & ) $1.38(1.03-1.84)$ \\
\hline Model $2^{\dagger}$ & $1.15(0.96-1.37)$ & 1.0 & $0.75(0.56-1.00)$ & $0.94(0.84-1.06)$ & $0.86(0.72-1.03)$ & $1.94(1.51-2.50)$ & $1.07(0.92-1.23)$ & $1.03(0.76-1.39)$ & $1.37(1.03-1.84)$ \\
\hline Model $3^{\ddagger}$ & $1.09(0.92-1.31)$ & 1.0 & $0.76(0.57-1.03)$ & $0.95(0.85-1.07)$ & $0.88(0.73-1.06)$ & $1.88(1.46-2.42)$ & $1.04(0.90-1.20)$ & $1.01(0.75-1.37)$ & $1.29(0.97-1.73)$ \\
\hline
\end{tabular}

